\title{
Public participation in health care quality
}

\author{
Lowell S Levin
}

With my presentation there will have been an even dozen Duncan lecturers. It is extraordinary how the work and character of William Henry Duncan has caused the selection of such a diverse array of themes. Each of the Duncan lectures, however, found in Dr Duncan's work a strand of common cause with their own interests. And I am no exception. Duncan knew from his experience with the authorities, be they governmental or professional, that for public health to advance it must build a public constituency of informed citizens. The horrendous poverty of Liverpool, its crowded housing and lack of sanitation were, of course, obvious to the middle class but the powerful link of such conditions with high levels of morbidity and mortality needed Dr Duncan's documentation to build the basis for public understanding of the public health prevention option. This may have been the first time that a purposeful effort was made to enlist public support for a specific public health action.

Since Duncan's day, of course, there has been a steady increase in the encouragement of public participation in moving the public health agenda forward. Progress toward full public participation has not, however, been constant or without professional/governmental resistance. Sharon Arnstein, an American citizen health advocate, developed nearly 25 years ago the so called "ladder of participation" that described eight levels of participation. These started with informing, consultation, and placation and moved to three degrees of what Arnstein referred to as "citizen power" - partnership, delegated power, and citizen control. ${ }^{1}$ Clearly Dr Duncan climbed the first several steps on the ladder and was probably inclined to seek public-professional partnership as well. But nearly a century had passed before serious strategic consideration was given to involving the public as partners in health planning, delegating specific power of self determination in health care, or placing citizens in full control of the health enterprise.

We are presently a long way from the latter and are still tentative about "partnership" and lay self determination in health. We in the health and related professions remain quite caught up in the exclusivity of our "qualifications" in health matters and view with suspicion the ability of ordinary citizens to provide criticism or even to comprehend the complexities of health actions, be they at the political or personal level. We are, at the same time, absolutely convinced of the scientific merit and wisdom of our professional expertise. Ordinary citizens have beliefs - we have knowledge. This, despite mounting evidence of public competence in health decision-making ${ }^{2}$ concurrent with mounting evidence of the fallibility of the medical and public health professions. ${ }^{3}$

Of course, these two realities are not usually juxtaposed, but professional critiques of the lay role in health have an undercurrent of defensiveness. The view is that the proponents of the lay role, especially in personal care, are reacting critically to limitations of professional care. ${ }^{4}$ Perhaps. But what this points out is the discomfort health professionals feel as they see the erosion of their power as health and health care become increasingly social ideas where many voices and many resources want to have their contributions acknowledged.

The popularisation of health does take its toll on traditional roles, traditional constructions of reality, and the egos invested in them. Is nothing sacred anymore, some ask? Does democratisation know no bounds? Will the time come when plebiscites will replace scientific inquiry to determine truth? Will citizen control, ending professional dominance, ${ }^{5}$ as we have grown to know and cherish it, destroy health gains already achieved? Or are we entering a new era of health development where lay and professional collaboration, with full professional and public oversight will bring us closer to the World Health Organization's idealistic goal of health for all? What is going on here and where might it take us.

In my time with you this evening, I want to respond to these questions as they redefine health as common property, in its achievement, maintenance, and restoration. I cannot profess an unbiased view of consumerism and health, because I could not get away with it for very long anyway. Too many of my British colleagues in the College of Health and the Patients' Association have shared panels or podia with me as we challenged what in earlier days we called the establishment. What saves you (us) from my bias now is that I no longer have to rely on impressions, anecdotes, and rhetoric.

Lay initiatives in personal health care Since the late 1970 s there has been an extraordinarily productive research effort, largely in the UK, USA, and Canada that documents the 
extent and quality of lay initiatives in personal health care, social care, and most recently in the heretofore sacred domain of quality assurance. This is not to say that we have reached the promised land of a full text on how any, much less all, aspects of lay health actions perform, but the research agenda now clearly specifies the work yet to be done. We have a map and now we have the financial support of government who were previously reluctant to invest in an area of study some felt was antiestablishment. After all, some argued, if levels of self care are shown to be high, will this not be an indication that government services have failed to meet needs? Or, as some third world observers cautioned, promoting lay self care may be a "sinister" plot to avoid government responsibility. ${ }^{6}$

Undoubtedly, some people in the industrialised countries feel the same way. ${ }^{7}$ In this country, it was Dr John Fry who in effect said "nonsense" to all of the above; self care is the base of the health care pyramid and essential for the efficacy of the overall health care system. ${ }^{8}$ A decade later John Last in his classic study of self care practices forced consideration of lay practices in "completing the clinical picture in general practice". ${ }^{9}$ Research began to build which documented the extent (Williamson and Danaher ${ }^{10}$ Pratt, ${ }^{11}$ Freer, ${ }^{12}$ ElliotBinns, ${ }^{13}$ Alpert, et $a l^{14}$ ) and efficacy of lay self care practices (Zapka, ${ }^{15}$ Knapp and Knapp, ${ }^{16}$ Litman, ${ }^{17} \mathrm{Katz}^{18}$ ).

\section{Self care - a threat to the status quo}

In 1975 , what turned out to be a landmark or at least benchmark international symposium on the "Role of the Individual in Primary Health Care", sponsored jointly by the University of Copenhagen and the University of California, Los Angeles was held in Copenhagen at the European headquarters of the World Health Organization. The symposium took a hard look at lay health care practices, clarified roles and functions, drew attention to relevant technical and social issues, and identified priority research needs. But acceptance of the lay contribution to health and especially to medical care was a tough struggle. Nothing came easy.

Indeed in my country, the government undertook a study of lay medical care practices which concluded that such practices represented "rampant empiricism", antithetical to the health and welfare of the American people. ${ }^{19}$ Never mind that 80 to $95 \%$ of all illness episodes were self cared for (and safely!). Never mind that 15 million people in the USA were in a given census year members of mutual aid groups. Twenty years ago my government, with the advice of health care authorities it is assumed, were seeking ways of stamping out the unauthorised practice of medicine albeit self directed within the family. Those who proposed expanding lay self care practices were viewed negatively by authorities, both governmental (regulatory) and professional (organised medicine). They were seen as promoting an "empowerment strategy", a serious threat to the status quo. And indeed it was.
The women's health movement challenged medical authority in the boldest and most courageous of ways. Some women's clinics and education centres were shut down and their personnel jailed for allegedly practising medicine without a license. These women were saying "enough!" to what they perceived as abuses in the professional medical treatment they received. They dared to "go public" about these abuses and arm women with the knowledge and skills to take charge of their own bodies. The do it yourself vaginal examination using a speculum became the symbol of their struggle.

\section{Self protection}

In America, it was the women's health movement, and in particular The Women's Health Book Collective in Boston, ${ }^{20}$ that first broadened the definition of self care to include concern for, and ways to protect oneself from, the hazards of professional medical services. Starkly put, women are seen by some health professionals as a disease. Many normal physiological phenomena are converted to pathologies, from puberty to birthing to menopause. Women are "exposed" to medical care five to six times as much as are men. In the USA and Canada, nearly $60 \%$ of women will not reach their 65 th birthday with an intact uterus! Caesarean section rates hover around 25\%. Mammography screening fails to meet known epidemiological criteria for use. Ultrasound is excessively used in pregnancy. And women are overdosed with unnecessary regimen of prescribed medications. One Canadian physician summed it up:

"Over the last 16 years of medical practice, I have seen many women suffer needlessly because their doctors did not really listen to them, told them that physically based complaints were all in their heads and treated normal events in a women's life as if they were diseases. Time and again I have seen women paying a heavy price for the careless prescription of antibiotics, birth control pills, hormones, and tranquilizers."21

In the United States, the relatively benign self care consumer movement began to reflect a concern for the quality of professional medical care and the personal skills required to be more self protecting. The challenges to the hegemony of medical professionals began to spread in the mid-70s beyond the borders of women's groups. A major rise in public awareness of the hazard of medical care came through the 1975 publication of Ivan Illich's severe critique of medicine as a source of multiple levels of iatrogenic complications. Many of you can recall the furore this little volume created in medical circles. Illich's work and his persona became an irresistible irritant. He hit a sensitive spot and opened public debate on a previously taboo topic: the fallibility of medicine. Who was this priest who dared to expose the secrets of priests of another calling? As a learned philosopher with international standing, Illich could not be dismissed lightly. Perversely, the health pro- 
fessionals could not get enough of him. Time and again he was asked to explain his position at conferences and seminars of medical practitioners and academics. His views began, as well, to attract the attention of lay voluntary health groups. He broadened awareness of the limits and hazards of medical care at physical, psychological, and socio-politicial levels.

\section{End of the age of innocence}

The age of public innocence regarding medical care and its supporting institutions was coming to a close in America. Soon a plethora of books on medicine's shortcomings began to make their way into the popular trade market. The most successful in the USA was Dr Robert S Mendelsohn's Confessions of a Medical Heretic in which the author ".... tells you how to guard yourself against the harmful impact upon your life of doctors, drugs and hospitals."22 A respected clinician, Mendelsohn was also chairman of the Medical Licensing Committee for the State of Illinois and a faculty member of the University of Illinois School of Medicine. His public testimony was a shock to the medical community. Some colleagues labelled him more a traitor than heretic. But public interest was keen, quickly making Confessions a best seller.

That same year (1979) Dr Richard Taylor, a member of the Doctors' Reform Society in Australia, wrote an equally audacious book, but a nonetheless meticulously documented account of the adverse effects of medical care. His book, Medicine Out of Control, had as its subtitle "the Anatomy of a Malignant Technology". ${ }^{23}$ Now, Australians are a kind and gentle people not ordinarily given to hyperbole, much less to frontal attacks on respected social institutions. But Taylor's critique seems to have struck a responsive chord even among some general practitioners who had reservations about medical specialists who they charged did not encourage patients to make informed decisions regarding the appropriateness and safety of high tech medical procedures.

Another publicly oriented trade book, this time by an Australian lawyer and journalist, concentrated its attack not only on the "huge hidden toll of medical malpractice in Australia, but also how the law enabled negligent and incompetent doctors to escape penalty ... [and] how medical defence organisations use an array of 'dirty tricks' to stifle legal action by patients." 24 Arguably biased as a lawyer, author Stephen Rice does seem to have done a careful job of documentation as if preparing a legal brief. His work tapped another aspect of public concern about the quality of care issues: the belief that the medical establishment is an impenetrable club with little possibility for ordinary citizens to gain access to performance data on practitioners or institutional care. Such restricted access to quality of care information diminishes patients' capacity to make personal care decisions as well as sound political judgements about medical care reform. With regard to patient access to information, one contributor to the Victorian (Australia) Law Reform Commission's report on Informed Decisions about Medical Procedures wrote:
"Other doctors, however, still cling to the notion that 'doctor knows best'! They believe that their patients expect the doctor to tell them what to do, rather than to encourage them to make their own informed decisions. Confronted by this attitude, patients are often confused; they do not know what information they should be given, how to ask for it, or what they should do if they think that they have not been properly informed or suitably treated." 25

Nor has the public been well informed about the efficacy of the medical care system. Even in medical care systems considered exemplary, such as Canada's, the overuse and sometimes misuse of high tech procedures is commonplace. Canadians are just now becoming aware of the reason for long waits for elective surgery, long emergency room queues and other apparent discrepancies between the image of having the best system and the reality of a "rationed" service. ${ }^{26}$

\section{Quality of medical care}

Now, in order to make clear the basis for the growing public concern for the quality of medical care, I offer some aspects of the American experience. Iatrogenic complications are not frivolous matters there. The table shows a few examples which will give some sense of the magnitude of the problem. ${ }^{27}$

I do not mean to suggest that American medical care or medical care in other industrialised countries is a disaster. But we cannot ignore that old aphorism: one third of medical encounters help, one third make things worse, and one third neither help or hurt.

Studies of the quality of medical care in the United States over the past 15 years, however, have shown no appreciable improvement in key indicators such as rates of nosocomial infection, medication errors, anaesthesia errors, unnecessary surgery (except the slight drop in caesarean sections), laboratory errors, and $x$ ray diagnostic errors. With accelerated use of technology there is further room for complications at the hands of inadequately trained or supervised operators, as in the case of laparoscopic surgery. ${ }^{29}$

Current strategies for quality control have not obviously improved the situation. The combined efforts of hospital infections committees, surgical and medical audits, quality assurance review boards, and medical licensing boards does not seem to have contributed to a significant gradient of improvement. Even a new USA government oversight programme that attempts to track the movement of incompetent health care providers has not been sufficient. Similarly, the USA system for reporting defective hospital equipment has had little effect on the use of such equipment. Government hospital accrediting agencies do review, inspect, and approve hospitals, but "in reality these organizations labor under inconsistent standards and yield poor inspection results .... missing two out of three quality-of-care problems related to physicians' care in hospitals." ${ }^{30}$ So it 
The quality of medical care - some aspects of the US experience

- Only 10 to $20 \%$ of all procedures currently used in medical practice have been shown to be efficacious in controlled trial (OTA 1978).

- The reporting of a procedure's overuse or obsolescence has a very slow impact on the practice of medicine (Rand Corporation/UCLA 1987).

- Nearly a quarter of all hospital admission and $15 \%$ of doctors' office visits are unnecessary; and $53 \%$ of time spent in the hospital is medically unnecessary.

- Five-10\% of American physicians are incompetent to practice medicine, not including those with incapacities such as drug abuse, alcoholism.

- Laboratory testing: approximately two thirds of tests are useless to irrelevant, with an overall $4 \%$ error rate. In 1985 this error rate represented 140 million test results.

- Approximately $5 \%$ of patients in hospital, according to a 1984 Harvard study "sustained injuries that resulted from their medical care and not the underlying disease". $1.35 \%$ was ascribed to medical negligence. ${ }^{28}$ This study, however, did not include a wide variety of treatment related injuries such as nosocomial infections, diagnostic errors, or unnecessary surgeries or unnecessary invasive testing.

- The nosocomial infection rate is now 5-10\% of hospitalised patients.

- The medication (hospital) error rate not using a unit-dose system averages $11 \cdot 6 \%$ of medication administrations.

- Five million surgical procedures are unnecessary (21\% caesarean section rate).

- Twenty two per cent of hysterectomies are unnecessary (mostly involving women under 40 years).

was inevitable that the public would perceive that its health interests were not being adequately protected by the government and professional agencies and that public pressure for reform was necessary.

\section{Lay health care is increasing}

At the same time, the strong base of public interest in personal health action in the USA keeps growing. Now there is increased access to the technologies of medical care (note the 10 billion dollar do it yourself medical equipment industry), greater access to effective medication (switch from prescribed to over the counter products), and above all a tremendous acceleration in health and medical information via books and magazines, electronic media (12 TV doctors), and syndicated health columns in the daily press. One estimate is that there are over 7000 book titles in the general category of do it yourself medical care. The range of subjects runs from standard protocols text, ${ }^{31}$ dealing with common medical problems, ${ }^{3233}$ selecting appropriate medications, ${ }^{34}$ to a plethora of holistic and alternative medical texts. ${ }^{35}$ There is also a modest literature on self protection in medical care, although its appeal is largely confined to a rather sophisticated audience. One of the earliest of these texts was written by a physician who was seeking to encourage a new kind of patient “... assertive, questioning, capable of making decisions that are vital to his survival."36 The latest book, When your Doctor Doesn't Know Best, is subtitled "229 Errors Even the Best Doctors Make and How to Protect Yourself". ${ }^{37}$

\section{The People's Medical Society}

America is arguably the world's most consumerist and litigious society. Americans have a core mistrust of government and professional associations devoted to the well being of their profession. And, as noted earlier, the reverse is true as well. American government agencies and health professional organisations, with few exceptions, were never keen on public empowerment in health. Professionals seem to hold all the cards. They are organised and, well financed, and influential with government authorities. The public, on the other hand, while increasingly better informed about health and medical care had no focal point for their views and priorities, until 1983 when America's first national health consumer organisation was formed. Well financed through a generous endowment by health book publisher, Rodale Press, the People's Medical Society began life with a sophisticated strategy to enroll members in every state. Eventually the People's Medical Society reached 115000 members, to become the largest consumer health organisation in America.

The goal of the organisation is to improve the quality of professional medical care through increasing public disclosuie of relevant data; mobilising public political action at all levels of government; empowering individuals to take self protective action in the use of medical care; and investigating and reporting the competence of health care providers and institutions. I shall give only a few examples of the actions taken in these areas.

The People's Medical Society has promulgated or vigorously supported laws requiring hospitals to disclose publicly and routinely data on nosocomial infection rates, rates of diagnostic and treatment errors, frequency of surgical procedures, caesarean section and hysterectomy rates, and the status of malpractice law suits against hospital health care personnel. With regard to political action, the society mounts highly focused membership communications campaigns addressed at legislators. As many as 45000 communications on behalf (or opposed to) a piece of health legislation have been directed at legislators in a 48 hour period. These have been very effective in expanding access to information, in tightening up serious penalties for medical malfeasance, and in providing safeguards against alcohol and drug impaired physicians. 
The society continues to press state governments to change from a physician licensure system to a certification system. This would include triannual written, oral, and practical testing of all physicians and certifying only those skills where competence is demonstrated. No more lifetime licenses would be issued. A certification approach would help assist patients select practitioners according to specific competencies, regardless of the speciality label. ${ }^{38}$ You can imagine the uproar this proposal is creating. On the other hand, during this tight budget period more and more legislatures are interested in saving the average of $\$ 400.00$ cost of incompetent care which is now added to each hospital bill!

\section{Central work of the society}

The central work of the society, however, concentrates on individual empowerment. A physician evaluation form is completed by members after each office visit and filed by the society for reference by other members. The evaluation covers 20 aspects of the physician contact for example waiting time, respect for patient integrity and privacy, quality of explanations provided, suggestions for self care and prevention, encouraging second opinions, etc. Physicians are invited to subscribe to the People's Medical Society "Code of Good Practice" which entitles them to be entered in the society's recommended list of physicians.

Quality control, it seems is most effective at the point of medical contact. Members are encouraged when possible to take a relative or friend along to the doctor, or otherwise tape record the encounter for further review at a less stressful time. If the physician objects to the presence of a friend or relative, or tape recording, members are advised to see another physician, if this is feasible.

The society helps members prepare for medical encounters. Self protection guides are available with such titles as Take this Book to the Hospital with you, ${ }^{39}$ Take this Book to the $\mathrm{Ob}$ stetrician with you, ${ }^{40}$ and Take this Book to the Gynaecologist with you. ${ }^{41}$ Several members reported that merely placing a copy of the hospital book at the bedside had a positive effect on the care givers' attitudes and performance!

The People's Medical Society undertakes periodic assessments of hospitals through surveys of physicians and nurses practising in a given catchment area. The results of their preferences and the rankings of hospitals are published widely and serve to remind the public that quality, as judged by people who should know, varies among hospitals. It demonstrates the importance of being selective, of increasing choice.

Public participation in assuring quality of medical care in the USA has become serious business, tough and unrelenting in its process of discovery and demands for reform. It uncovers unpleasant facts about the real work of medical care and urgently challenges government and professionals to take action now. When it was seen, for example from the records of medical licensing boards in the 50 American states that only a tiny portion of malpractising physicians are censured, much less barred from practice, the People's Medical Society began a campaign to make all membership on medical licensure and examining boards exclusively lay - no physicians - and to move to a jury system where expert medical and scientific witnesses could be heard. Lay representation also is being argued for on hospital medical and surgical audit teams. These are seen as necessary remedies in an environment where there is not now any built in system for public accountability.

\section{The style of confrontation}

You might have guessed that the style of the People's Medical Society is irreverent and provocative. This style, in itself, serves to communicate that it is alright, legal, ethical, and possible to criticise sacred cows openly and to challenge the conspiracy of silence within the health professions. Anger is a healthy emotion and fear of retribution is far less a threat to a person's well being that passivity in the face of doubtful medical competence. Those messages seem to be taking hold in an America where medical care was the last holdout against consumerism.

I am told by friends in Europe and Canada that a confrontational style is typically American. It would not work elsewhere, they say. Perhaps not. But one way or the other, the issues of information disclosure, equity, accountability, and empowerment will have to be addressed everywhere if we wish to achieve the promotion of health as envisioned in the Declaration of Alma Ata and in the World Health Organization's Ottawa Charter. ${ }^{42}$ An initiative is now being considered in Hungary to organise a panEuropean association of health consumer organisations. Countries of central and eastern Europe and the newly independent states of the former Soviet Union present a propitious opportunity to develop a consumer voice in health. The optimistic view is that such an innovation can take root in this period of transition, where suspicion of government and authority in general runs high and the strategies of democracy are still novel and inviting.

\section{The future}

As chair of the board of directors of the People's Medical Society, and at the same time a longtime member of the public health establishment (and an academic at that!), I am well aware that an agenda of nihilism, doctor bashing, and general antiestablishmentism would be shallow, self serving, and ultimately counterproductive. We must avoid replacing one tyranny with another. This can be accomplished by continuing to expand the partners in dialogue among public interest groups and the health professions where the partnership is mutually respectful. We should not misconstrue or be embarrassed by the passion in the voices on either side.

William Henry Duncan was nothing if he was not courageous. He took on the establishment with strong and persistent pressure. And he 
knew the value of a public constituency to move the political agenda.

Were he with us today, I believe he would be as undaunted in pursuit of solutions to problems from within the health professions and health system as he was in pursuit of problems within the community. He had to convince people of the environmental threat, its causes and its remedies, in the face of other beliefs and social priorities. I doubt he would tolerate any obstacle, not even his own professional identity, to bringing people around to a reasoned solution. We could use a little of that courage today in public health to evaluate our contribution to health on a full continuum from -1 to +1 . Promoting health as Hippocrates emphasised, starts with doing no harm. Not a bad idea.

1 Arnstein S, as quoted in Schiller PL, Steckler A, Dawson L, Patton F. Participatory planning in community health education. Oakland, CA Third party Publishing Company: 1987:20-21.

2 Carlson R, Newman B, eds. Issues and trends in health. St. Louis: CV Mosby, 1987.

3 Skrabanek P, McCormick J. Follies and fallacies in medicine. Buffalo, NY: Prometheus Books, 1990.

4 Round table discussions. World Health Forum. 1981;2(2): 191-201.

5 Friedson E. Professional dominance: The social structure of medical care. New York: Atherton Press, 1970.

6 Deria A. Self-Care puts the onus on the people themselves. World Health Forum 1981;12(2):194.

7 Katz AH, Levin LS. Self-care is not a solipsistic trap: A reply to critics. Int $\mathcal{f}$ Health Serv 1980;10:329-36.

8 Fry J. Self-care, its place in the total health care system. A report by an independent working party. London: Guy's Hospital, 1973:15.

9 Last J. The iceberg: Completing the clinical picture in general practice. Lancet 1963;ii:28-31.

10 Williamson JD, Danaher K. Self-care in health. London Croom-Helm, 1978.

11 Pratt L. The significance of the family in medication. fournal of Comparative Family Studies. 1973;4:13-31.

12 Freer CB. Self-care a health diary study. Med Care 1980 . 18:853-61.

13 Elliott Binns CP. An analysis of lay medicine. fR Coll GP 1973;23:255-64

14 Alpert JJ, Kosa J, Haggerty RI. A month of illness and health care among low income families; Public Health Rep 1972;82:1004-12.

15 Zapka J, Averill BW. Self-care for colds: A cost effective alternative to upper respiratory infection management. Am F Public Health 1979;69:814-16.
16 Knapp DA, Knapp DE. Decision-making and self-medication: preliminary findings. Am F Hospital Pharm 1972 29:1004-12.

17 Litman TJ. The family as a basic unit in health and medica care: A social-behavioral overview. Soc Sci Med 1974;53: 495-519.

18 Katz HP, Clancy RR. Accuracy of home throat culture program: A study of parent participation in health care. program: A study of parent
Pediatrics 1974;53:687-91.

19 National Analysts Inc. A study of health practices and opinions. Springfield, VA: National Technical Information Service, US Department of Commerce; 1972, 343

20 The Boston's Women's Health Book Collective. Our bodies, ourselves. New York: Simon and Schuster, 1971.

21 Carolyn De Marco. Medical malpractice. In: Hinks KM ed. Misdiagnosis: women as a disease. Allentown: People's Medical Society, 1994:59.

22 Mendelsohn RS. Confessions of a medical heretic. Chicago: Warner Books, 1979.

23 Taylor R. Medicine out of control. Melbourne: Sun Books, 1979.

24 Rice S. Some doctors make you sick. Auckland: Angus and Robertson, 1988

25 Skene Dust jacket: You, your doctor and law. Oxford University Press, Melbourne, 1990:IX.

26 Rachlis M, Kusher C. Second opinion. Toronto; Collins, 1989.

27 Inlander C, Levin LS, Weiner E. Medicine on trial. New York: Prentice Hall Press, 1988:308

28 Center for Medical Consumers. Health Facts. 1990; $\mathbf{X V}(132): 1$.

29 Altman LK. Standard training in laparoscopy found inadequate. New York Times. Dec 14, 1993:C3.

30 Anonymous. Quality of care in the hospital. People's Medical Society Newsletter 1992; 11:1.

31 Vickery DM, Fries JF. Take care of yourself. Reading, MA: Addison-Wesley Publishing Company, 1986.

32 Simons A, Hasselbring B, Castleman M. Before you call the doctor. New York: Fawcett Columbine, 1992.

33 Howell M. Healing at home. Boston: Beacon Press, 1978

34 Graedon J, Graedon T. Graedon's best medicine: from herbal remedies to high tech Rx breakthroughs. New York: Bantam Books, 1991

35 Pelletier KR. Holistic medicine: From stress to optimum health. New York: Delacorte Press, 1979.

36 Belsky MS, Gross L. How to choose and use your doctor. New York: Arbor House, 1975, jacket.

37 Podell RN. When your doctor doesn't know best. New York: Simon and Schuster, 1994

38 Andrews L. Deregulating doctors. Allentown, PA: People's Medical Society, 1986.

39 Inlander CB, Weiner E. Take this book to the hospital with you. New York: Pantheon Books, 1991.

40 Morales K, Inlander CB. Take this book to the obstetrician with you. Reading, MA: Addison-Wesley Publishing Inc, 1991 .

41 Maleskey G, Inlander CB. Take this book to the gynecologist with you. Reading, MA: Addison-Wesley Publishing Inc, 1991 .

42 Ottawa charter for heath promotion. World Health Organization, Health and Welfare Canada, Canadian Public Health Association, No. 17-21, Ottawa, Canada, 1986. 